\title{
Dossier
}

Volumen 36, nro. 102, agosto 2021 ISSN 0718-1299

\section{conducen a la vivienda social? Trayectorias residenciales como factor de diferenciación}

Recibido: 2021-02-02

Aceptado: 2021-07-28

\section{Cómo citar este artículo:}

Najman, M. (2021). ¿Todos los caminos conducen a la vivienda social? Trayectorias residenciales como factor de diferenciación. Revista INVI, 36(102), 157-182. https://doi.org/10.4067/S0718-83582021000200157

Este trabajo fue realizado en el marco de la tesis doctoral de la autora y contó con un financiamiento de beca doctoral del Conicet.

\section{Mercedes Najman}

Conicet - Instituto de Investigaciones Gino Germani, Facultad de Ciencias Sociales, Universidad de Buenos Aires, Buenos Aires, Argentina,

mercedesnajman@gmail.com

http://orcid.org/0000-0002-7690-6090 


\section{¿Todos los caminos conducen a la vivienda social? Trayectorias residenciales como factor de diferenciación}

\section{Resumen}

Este artículo propone un análisis de las características de los habitantes de la vivienda social localizada en la Ciudad Autónoma de Buenos Aires y de los efectos que experimentan tras llegar a estos barrios desde un abordaje enmarcado en el enfoque de la movilidad espacial y de los estudios biográficos. Mediante la construcción de una tipología de las trayectorias residenciales de los destinatarios de la vivienda social hecha a partir de un encuadre cuantitativo de análisis de secuencia multinivel, se problematiza la caracterización homogeneizante que la política habitacional suele emplear sobre esta población. Los resultados demuestran que las trayectorias residenciales previas de los destinatarios dan cuenta de diferentes niveles de vulnerabilidad y problemáticas diversas frente a las cuales la política habitacional, ignorando tales particularidades, ha ofrecido una solución estandarizada que genera efectos limitados sobre estos hogares. En este sentido, las trayectorias residenciales se han perfilado como un mecanismo de diferenciación que despierta efectos desiguales de la política sobre las condiciones habitacionales de sus destinatarios.

Palabras clave: Trayectorias residenciales, vivienda social, movilidad residencial, Buenos Aires (Argentina). 


\section{Abstract}

This article proposes an analysis of the characteristics of the inhabitants of social housing located in the City of Buenos Aires and the effects they experience after arriving in these neighborhoods from an approach framed in the spatial mobility and biographical studies. Through the construction of a typology of the residential trajectories of the recipients of social housing from a quantitative framework of multichannel sequence analysis, the homogenizing characterization that housing policy usually employs on this population is problematized. The results show that the previous residential trajectories of the recipients present different levels of vulnerability and diverse problems against which the housing policy, ignoring such particularities, has offered a standardized solution generating mainly limited effects on these households. In this sense, residential trajectories have emerged as a differentiation mechanism that awakens unequal effects of the policy on the housing conditions of its recipients.

\section{Do all roads lead to social housing? Residential trajectories as a differentiating factor}

Keywords: Residential trajectories, residential mobility, social housing, Buenos Aires (Argentina). 


\section{*.*vis revistainvi}

\section{Introducción}

Las políticas de vivienda social orientadas a los sectores populares en la Ciudad de Buenos Aires definieron tradicionalmente a sus destinatarios bajo una categoría homogénea, igualando las características, necesidades y prácticas residenciales de estos hogares (Najman, 2020). A pesar de que, como señala Bartolomé (2008), el solo hecho de ser afectado por un proyecto o política no define a un grupo en un sentido sociológico ya que no implica la existencia de atributos sociales comunes, los diseños y modos de implementación de estas políticas tendieron a definir a sus destinatarios como un grupo social con características indiferenciadas. Sostenemos que esta definición se desprende y a la vez colabora con la imposición de formas estandarizadas en la construcción de vivienda por sobre las formas heterogéneas y particulares de habitar la ciudad de sus destinatarios, generando profundas consecuencias en los efectos de tales políticas sobre las condiciones de vida de sus habitantes (Defensoría del Pueblo de la Ciudad Autónoma de Buenos Aires, 2015; Giglia, 1996).

Si bien existe un nutrido campo de investigaciones que ha problematizado los efectos de la vivienda social en sus destinatarios poniendo el foco en la emergencia de problemáticas sobre las nuevas formas de habitar (Giglia, 1996; Girola y Thomasz, 2014; Zapata, 2013), poco se conoce sobre los efectos diferenciales de estas políticas sobre las biografías de sus habitantes, e incluso se sabe poco sobre los recorridos que estos hogares desarrollaron antes de ingresar a la vivienda social. Por este motivo, aquí proponemos problematizar la condición homogénea de los destinatarios de la vivienda social a partir de un análisis de sus trayectorias residenciales y de los efectos diferenciales que despertó la política habitacional en estos hogares. Ponemos el foco, tanto en términos metodológicos como teóricos, sobre las trayectorias residenciales de los destinatarios como factor de diferenciación. Llevamos adelante un análisis de los recorridos residenciales que estos hogares desarrollaron antes de ingresar a la vivienda social, indagando si los mismos expresan distintos modos de habitar, situaciones biográficas de exclusión territorial disimiles, y diversas estrategias y derroteros en torno al acceso a los valores de uso complejo que ofrece la ciudad (Bourdieu, 1999; Harvey, 1977). Asimismo, tal como señala Bartolomé (2008), estos distintos recorridos operan sobre los sentidos que adopta la llegada a la vivienda social, configurando efectos diferenciales. Buscamos identificar en qué medida y de qué modo estas políticas generaron efectos distintos sobre el acceso a la ciudad de sus destinatarios, considerando que llegan a la vivienda social desde diferentes tipos de inscripción territorial y con trayectorias residenciales heterogéneas.

Luego de esta introducción, el artículo presenta sintéticamente el enfoque teórico metodológico de la movilidad espacial, haciendo foco en la movilidad residencial y más precisamente en las trayectorias residenciales como un factor de diferenciación. Posteriormente, se menciona la estrategia metodológica implementada y se da lugar a la presentación y discusión de los resultados a partir de dos líneas de análisis: las características de los distintos tipos de trayectorias residenciales de sus destinatarios y los efectos diferenciales de la vivienda social. Finalmente, en un último apartado, además de resaltar los principales hallazgos del análisis realizado, se proponen algunas reflexiones en torno a las potencialidades de los estudios de movilidad espacial para comprender diversos fenómenos urbanos, especialmente en cuanto a la posibilidad de pensar y continuar explorando el peso de las trayectorias residenciales como un factor de diferenciación. 


\section{Trayectorias residenciales como un factor de diferenciación: mirando desde la lente de la movilidad}

A partir del enfoque teórico metodológico de la movilidad espacial -particularmente residencial- y de los estudios biográficos, este trabajo se propone generar un aporte al campo de conocimiento de las políticas habitacionales.

Entendemos a la movilidad espacial como la habilidad para moverse en el espacio, incluyendo tanto movimientos del lugar de residencia como movimientos diarios (Wunsh y Termote, 1978, en Pinto da Cunha, 2012). Los distintos tipos movilidad espacial se desprenden de los modos en que se vinculan los ejes espaciales y temporales de los desplazamientos (Dureau, 2004). Aun reconociendo la multiplicidad de prácticas de movilidad espacial, aquí nos enfocamos en la movilidad residencial.

Palomares-Linares et al. (2017) definen a la movilidad residencial en sentido amplio como todo tipo de desplazamiento que implique un cambio de residencia. Estos cambios pueden referirse a procesos de migración interurbana o a movimientos intraurbanos (al interior de una misma ciudad), aunque como veremos más adelante estos tipos de desplazamiento presentan connotaciones distintas. Estos movimientos traducen prácticas por medio de las cuales los hogares buscan acceder a las condiciones residenciales que perciben como necesarias (Clark, 2013). Desde ya, las prácticas de movilidad residencial no siempre satisfacen estas necesidades. Por el contrario, estas podrían entenderse como el resultado del cruce entre las necesidades o expectativas habitacionales de los hogares y las oportunidades habitacionales, considerando que además ambas dimensiones se encuentran condicionadas por la posición social de los hogares y su percepción sobre la misma, sus estilos de vida y las condiciones del hábitat (Knox, 1982 en Di Virgilio, 2008). Asimismo, los márgenes de acción de los hogares en materia de hábitat se ven condicionados por factores macro-espaciales tales como la política de vivienda vigente, la dinámica del mercado de trabajo y el de suelo y vivienda, entre otros (Dieleman, 2001; Pooley, 1997).

Clark (2013) señala además que las necesidades residenciales que los movimientos buscan equilibrar suelen desprenderse de cambios provocados por determinados eventos en la vida de los sujetos. Si bien numerosos estudios han centrado su análisis en el papel que estos eventos (momentos del ciclo de vida, casamientos y separaciones, nacimientos y defunciones, cambios laborales, etc.) desempeñan sobre las prácticas de movilidad residencial, aquí retomamos la línea de trabajos que se concentraron en la dimensión espacial y territorial de estos movimientos (Di Virgilio, 2008; Ryan y Whelan, 2010; entre otros). Estos estudios pusieron el acento en los territorios como elementos estructurantes de las prácticas de movilidad residencial y, a la vez, en las inscripciones territoriales de los hogares que estos movimientos visibilizan. Desde esta perspectiva, Di Virgilio (2008) define operativamente a la movilidad residencial como aquellos cambios de lugar de residencia que impliquen una modificación en la localización o tipo de vivienda; y/o en los arreglos en relación a las modalidades de tenencia jurídica. 


\section{*.*vis revistainvi}

Mediante estas prácticas, los hogares pueden transformar las posiciones que ocupan en el territorio y las características de dichas ocupaciones (Lévy, 1998). Si bien en muchos casos la movilidad residencial no conduce a modificaciones sustanciales del lugar que los hogares ocupan en la estructura urbana, cristaliza un proceso de lucha por la apropiación del espacio urbano (Bourdieu, 1999; Cosacov, 2014). Estas luchas disputan el derecho a gozar de los avances de la vida urbana (Lefebvre, 1968) y al uso y disposición del espacio urbano y sus externalidades (Oszlak, 1991).

Sobre este punto es preciso introducir algunas distinciones conceptuales sobre los movimientos residenciales intra e interurbanos. Para los propósitos de nuestro estudio la principal diferencia a señalar radica en que los movimientos migratorios involucran un cambio de la estructura urbana (Oszlak, 1991) en la que los hogares se inscribían previamente. Se trata de un movimiento que produce un cambio de unidad territorial funcional, de espacio de vida colectivo al conjunto de la comunidad urbana (Palomares-Linares et al., 2017). Un cambio de ciudad implica el arribo a nuevas lógicas espaciales de funcionamiento del mercado de vivienda y de trabajo (Howley, 2009) y de distribución de los bienes y servicios urbanos. Los cambios residenciales migratorios no nos permiten entonces advertir si estos movimientos introducen cambios sobre las posiciones que estos hogares ocupan en la estructura urbana. Mientras que los movimientos intraurbanos, al inscribirse en una misma unidad territorial funcional, si permiten hacerlo.

El conjunto de movimientos residenciales - intra e interurbanos- que se producen sucesivamente a lo largo de la vida de un individuo u hogar configura la trayectoria residencial del mismo (Di Virgilio, 2008). En tanto herramienta analítica, las trayectorias residenciales permiten poner en diálogo el enfoque de la movilidad espacial con la tradición de estudios biográficos o de curso de vida. Los estudios biográficos de curso de vida (Elder, 1991) reconocen distintas trayectorias (de empleo, educativas, familiares, residenciales, etc.) y señalan a estos cursos de vida como elementos diferenciales. Tal como sostiene O'Rand (1996, 2001), los procesos de estratificación pueden pensarse en clave biográfica, ya sea a través de los capitales y los riesgos presentes en el curso de vida. Desde esta perspectiva nos preguntamos si, a lo largo de sus vidas, los habitantes de la vivienda social fueron configurando recorridos heterogéneos que dan cuenta de situaciones de exclusión socio-territorial diversas. Caroline Dewilde (2003) señala además que estos diferentes cursos de vida pueden presentar efectos distintos frente a un mismo evento relevante, es decir que podemos pensar a las trayectorias residenciales no solo como prácticas estructuradas sino también estructurantes en la medida que operan como un elemento de diferenciación. 


\section{Metodología: construyendo una tipología de las trayectorias residenciales de los habitantes de la vivienda social}

Para reconstruir y analizar las trayectorias residenciales previas al ingreso a la vivienda social desarrollamos un análisis cuantitativo longitudinal en base encuestas biográficas retrospectivas a los habitantes de tres barrios de vivienda social ${ }^{1}$ construidas en distintas épocas y en distintas posiciones urbanas dentro de la Ciudad de Buenos Aires.

\section{Figura 1.}

Ubicación de los barrios de vivienda social analizados en la Ciudad de

Buenos Aires.

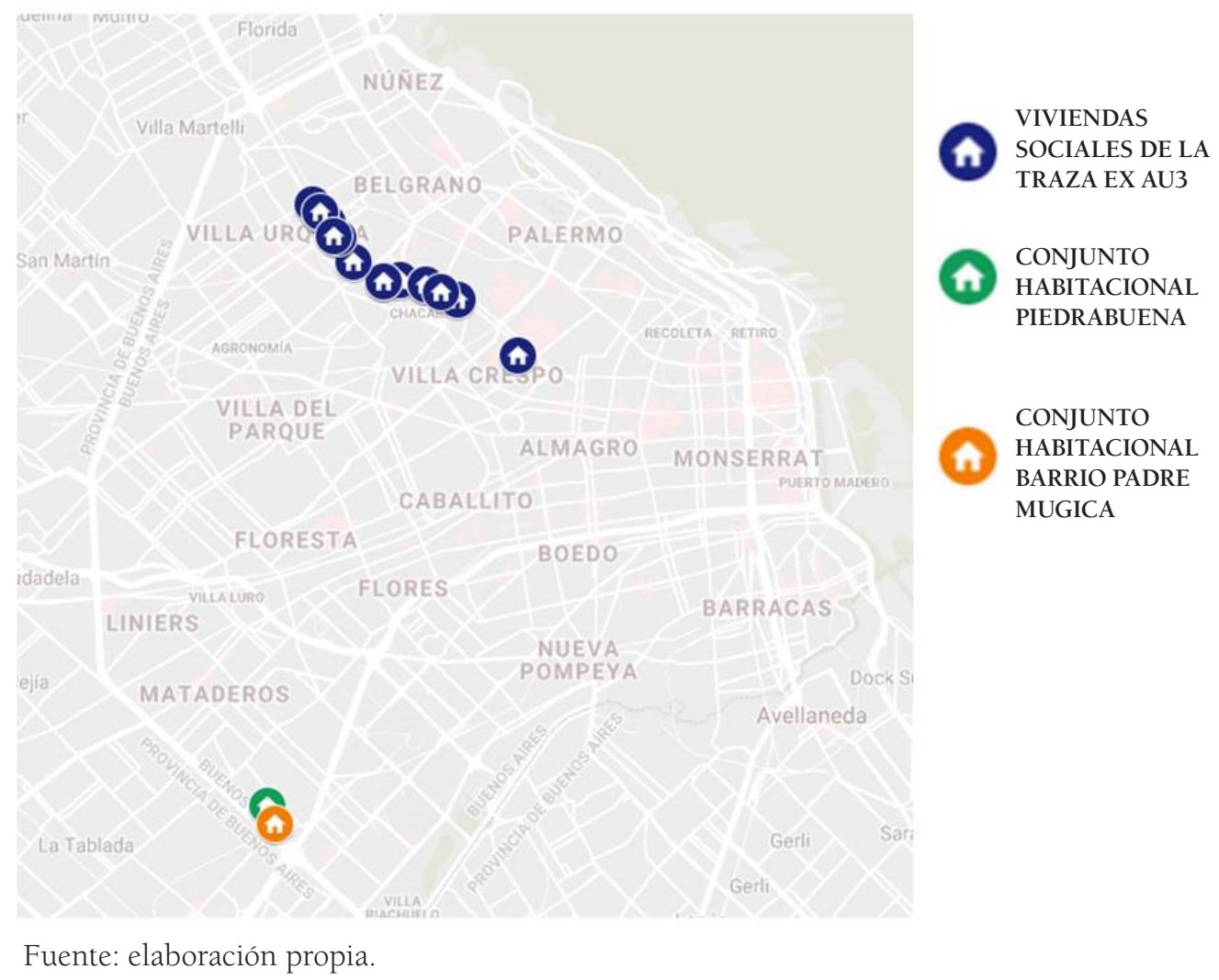

$\overline{1}$ Puede encontrarse mayor detalle sobre los barrios de vivienda social y las políticas que les dieron origen en Najman (2020). 


\section{*.*vis revistainvi}

El conjunto urbano Comandante Piedrabuena fue proyectado en el marco del Plan Alborada, siendo un representante de las denominadas "políticas tradicionales" de vivienda social en la Ciudad y su poblamiento inició a comienzos de la década del 80. Las 2100 viviendas, construidas en una tipología de corte moderno y funcionalista, fueron concebidas para alojar a población de villas, habitantes de conventillos y familias en viviendas obsoletas. En segundo lugar, el conjunto urbano barrio Padre Mugica comienza a construirse en el año 2008 a partir de las denominadas "nuevas políticas de vivienda social", más precisamente como parte de los Planes Federales de Construcción de Vivienda e inicialmente en el Programa Sueños Compartidos. Se caracteriza por una tipología constructiva de menor escala (780 viviendas y sin equipamientos) y por ser destinada a hogares que sufrieron relocalizaciones en el marco de procesos de judicialización desde distintas villas y asentamientos de la ciudad. Ambos conjuntos se encuentran a poca distancia (ver Figura 1) en el barrio de Villa Lugano, Comuna 8. Se trata de una zona relegada que supera ampliamente los niveles de precariedad habitacional y de vulnerabilidad del promedio de la ciudad. Presenta además una calidad deficiente e insuficiente de equipamientos y servicios, haciendo de este territorio tradicionalmente privilegiado para la construcción de vivienda social, una zona desvalorizada y desfavorecida. Por último, las viviendas sociales construidas en el marco del Programa de Recuperación de la Traza de la EX AU3, integran también las denominadas "nuevas políticas" e incluso, son contemporáneas a las viviendas del barrio Padre Mugica. Sin embargo, este caso se distingue de los anteriores por su tipológica arquitectónica en edificios de baja densidad y dispersos en la trama urbana y por su ubicación en una zona que atraviesa un acelerado proceso de renovación urbana (barrios de Villa Urquiza, Villa Ortúzar y Chacarita). Estas unidades fueron destinadas a hogares que vivían bajo la modalidad de ocupantes en esta misma zona, cuyas viviendas fueron demolidas durante el proceso de renovación urbana.

El diseño muestral del estudio permitió obtener resultados representativos al interior de cada uno de los conjuntos de vivienda social. La muestra fue calculada sobre una selección aleatoria de 282 hogares a partir de un conteo de 2937 viviendas desarrollado en recorrido de campo. Sobre estos hogares se aplicó la Encuesta de Movilidad Espacial (EME)2 , captando datos longitudinales retrospectivos sobre la historia residencial, educativa, familiar y laboral del entrevistado representante del hogar (de aquí en más "ego") (Dureau et al., 2011). En función de los requisitos del método de análisis, realizamos un recorte del conjunto de hogares seleccionado solo a 240 ego $^{3}$ en la medida en que: ingresaron a la vivienda social con 20 años o más y que al llegar a estas viviendas fueron representantes de un hogar independiente (autónomo o no).

2 Aplicada por el Área de Estudios Urbanos del Instituto de Investigación Gino Germani (FSoc-UBA) durante los años $2014-2019$.

3 Cabe destacar que, como dos de los barrios bajo estudio fueron construidos posteriormente al último censo de población, no fue posible contar con datos demográficos del universo, y el control de la por sexo y edad se realizó con base a los datos poblacionales obtenidos por la misma encuesta. 


\section{* revistainvi}

\section{Tabla 1.}

Características de la muestra.

\begin{tabular}{|c|c|c|c|c|c|}
\hline $\begin{array}{l}\text { Barrio de } \\
\text { vivienda social }\end{array}$ & $\begin{array}{l}\text { Comandante } \\
\text { Piedrabuena (33\%) }\end{array}$ & $\begin{array}{l}\text { Barrio Padre } \\
\text { Mugica (39\%) }\end{array}$ & $\begin{array}{l}\text { Viviendas sociales } \\
\text { Ex AU3 }(28 \%)\end{array}$ & & \\
\hline $\begin{array}{l}\text { Edad de ingreso a } \\
\text { la vivienda social }\end{array}$ & Hasta 25 (14,6\%) & $\begin{array}{l}\text { De } 26 \text { a } 30 \\
(20,4 \%)\end{array}$ & De 31 a 40 (32\%) & De 41 a $50(16,7 \%)$ & $\begin{array}{l}\text { Mayores } \\
\text { de } 50 \\
(16,2 \%)\end{array}$ \\
\hline Sexo & Mujer (62\%) & Varón (38\%) & & & \\
\hline $\begin{array}{l}\text { Lugar de } \\
\text { nacimiento }\end{array}$ & $\begin{array}{l}\text { Otros países o } \\
\text { provincias }(46 \%)\end{array}$ & $\begin{array}{l}\text { Gran Buenos } \\
\text { Aires (22\%) }\end{array}$ & $\begin{array}{l}\text { Ciudad de Buenos } \\
\text { Aires - Barrios más } \\
\text { valorizados (16\%) }\end{array}$ & $\begin{array}{l}\text { Ciudad de Buenos } \\
\text { Aires - Barrios menos } \\
\text { valorizados (16\%) }\end{array}$ & \\
\hline
\end{tabular}

Fuente: elaboración propia.

Trabajamos con aquellas variables que nos permitieron reconstruir las trayectorias residenciales, recuperando la definición territorial de las mismas. Analizamos para cada año de vida las modalidades de inscripción territorial considerando el modo en que se vincularon tres dimensiones: el tipo de hábitat, el tipo de arreglo residencial y tipo de localización (ver Figura 2). Cada una de estas dimensiones puede variar independientemente de la otra, por lo que se considera como cambio residencial a cualquier alteración en estos estados. 
Figura 2.

Dimensiones de las trayectorias residenciales.

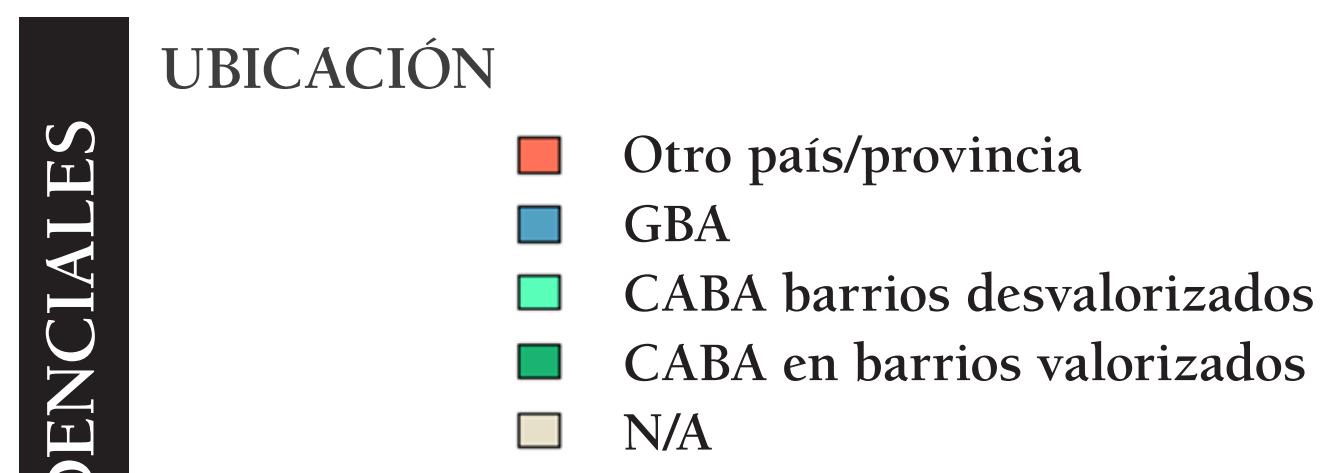

TIPO DE HÁBITAT

$\square$ Habitat informal

$\square$ Solución estatal

$\square$ Habitat formal

\section{ARREGLO RESIDENCIAL}

$\square \quad$ Allegamiento, viv colectiva y otros

$\square \quad$ Alquiler informal

$\square$ Propiedad informal u ocupante

$\square \quad$ Alquiler formal

$\square$ Propiedad formal

Fuente: elaboración propia. 


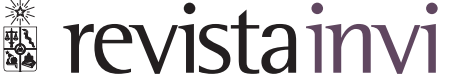

Las categorías de la localización ${ }^{4}$ reagrupan jerárquicamente las ubicaciones geográficas en relación a las zonas de mayores externalidades urbanas (ver Figura 3). La primera categoría (otros países o provincias) permite diferenciar las etapas que no se inscriben en la estructura urbana local, y las siguientes permiten distinguir las etapas que se emplazan en distintas localidades del Gran Buenos Aires y en dos zonas diferenciadas de la Ciudad Autónoma de Buenos Aires a partir del valor promedio de venta de inmuebles por barrio (medida que se relaciona directamente con las características de equipamiento y posición urbana de los mismos).

\section{Figura 3.}

Localización en el AMBA de las categorías de la variable Ubicación.

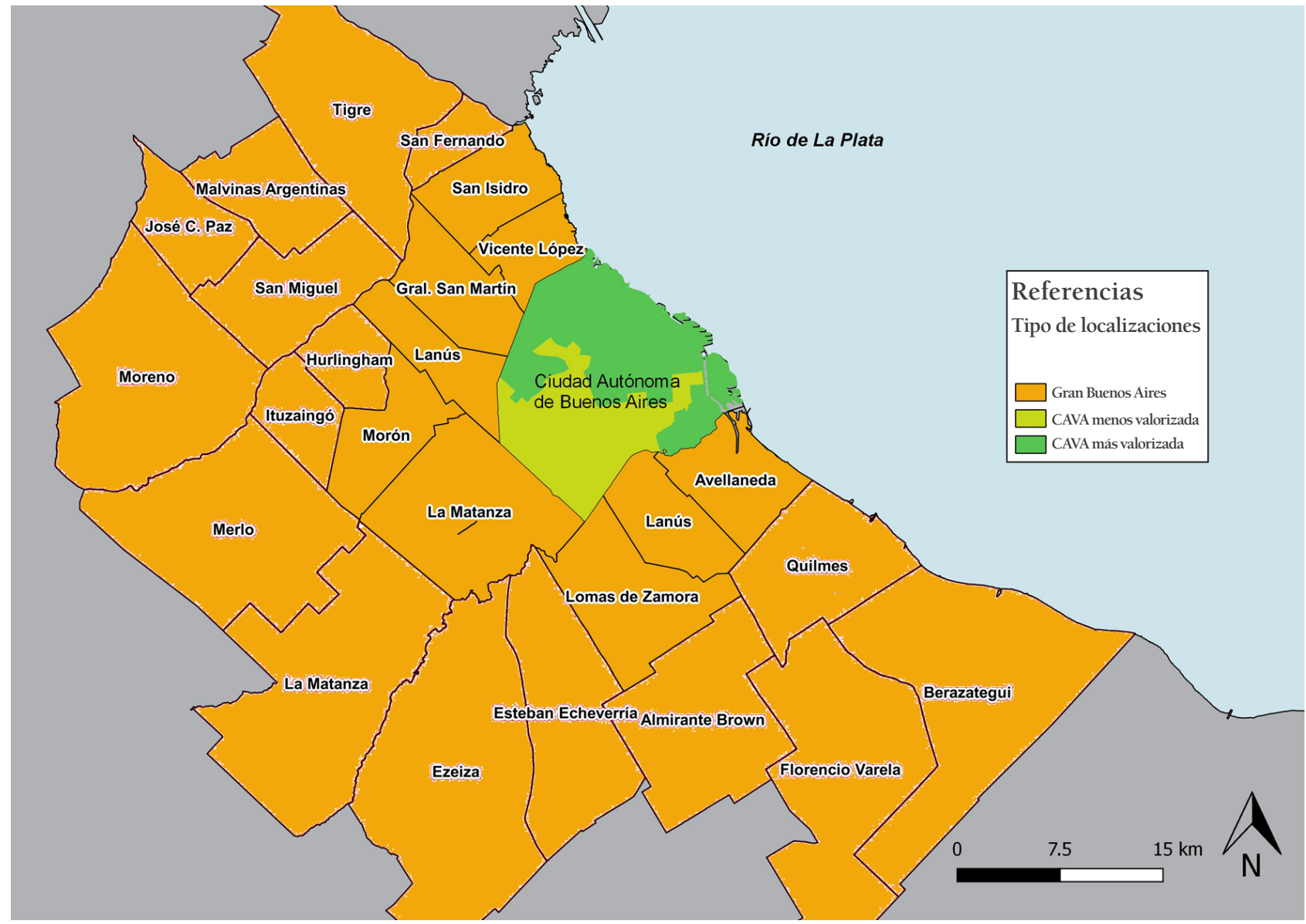

Fuente: elaboración propia.

$4 \quad$ La categoría GBA reúne los años de vida en que ego residió en distintas localidades del Gran Buenos Aires, mientras que la tercera y cuarta categoría diferencian dos zonas de la Ciudad Autónoma de Buenos Aires a partir del valor promedio de venta de inmuebles por barrio. 


\section{*.*vis revistainvi}

En segundo lugar, se consideran los diferentes tipos de hábitat o mercados de tierra y vivienda en los que los hogares se inscriben en cada etapa, permitiendo diferenciar las distintas maneras de producción del espacio habitacional (Mera et al., 2015). Y finalmente, la tercera dimensión recoge los arreglos residenciales (jurídicos o no) desarrollados por los hogares para acceder a la vivienda, los cuales involucran diferentes modalidades de tenencia de las viviendas y de organización del hogar.

Mientras que la localización de las viviendas muestra las posiciones diferenciales -y jerárquicas como consecuencia de la estructura urbana desigual que presenta Buenos Aires (Oszlak, 1991)- que los hogares ocupan en la ciudad, las tipologías de hábitat y los arreglos residenciales dan cuenta de la matriz formalizante o informalizante de los movimientos residenciales. Tal como identificó Di Virgilio (2008), como consecuencia de las características del mercado inmobiliario de esta ciudad y de los valores socioculturales presentes en su estructuración, las transiciones de los arreglos residenciales suelen tener una connotación jerárquica en clave de la informalidad urbana y se vuelven un elemento indispensable para analizar las posiciones que los hogares ocupan en la ciudad (Di Virgilio, 2008).

Bajo el propósito de identificar patrones comunes y diferenciales entre las distintas trayectorias residenciales que los habitantes de la vivienda social desarrollaron antes de ser destinatarios de estas políticas, se construyó una tipología mediante un análisis exploratorio de secuencias de alineación óptima bajo la técnica multicanal utilizando el paquete TraMineR (Gabadinho et al., 2011)5. Estos métodos buscan caracterizar el orden cronológico de los eventos para visibilizar la homogeneidad y heterogeneidad de los cursos de vida (Martínez Salgado y Ferraris, 2021) mediante la aplicación de algoritmos de agrupación que consideren el factor temporal y las distintas dimensiones de un mismo fenómeno (Gauthier et al., 2010; Helske et al., 2018; Ritschard y Studer, 2018).

El análisis multicanal de las trayectorias se realizó sobre los 20 años anteriores de la llegada de ego a la vivienda social. Se sincronizaron los cursos de vida en torno a un evento específico (Colombi y Paye, 2014): el ingreso a la vivienda social, truncando las trayectorias por derecha. Además, por los requisitos del método de análisis utilizado, las trayectorias se truncaron por izquierda considerando los 20 años previos. Sin embargo, con el objetivo de considerar la capacidad de ciertos factores de origen para condicionar los cursos de vida, a lo largo del análisis se incorporan datos que dan cuenta de las características de la inserción territorial de los ego en su hogar de nacimiento.

Mediante la técnica multicanal, hemos calculado seis clusters a partir del tipo de relaciones secuenciales que se producen entre las tres dimensiones residenciales a lo largo de la vida de los encuestados. Se identificaron seis "tipos ideales" de trayectoria residencial, a partir del criterio de mayor homogeneidad interna y heterogeneidad en relación a los otros, considerando los estados que las tres variables consideradas adoptaron durante los recorridos y sus vinculaciones. Asimismo, se interroga en qué medida estos tipos de trayectoria inciden sobre los efectos diferenciales que la vivienda social ha despertado sobre las condiciones de inserción socioterritorial de estos hogares.

5 Todos los procesamientos fueron realizados en el programa estadístico R (R Core Team, 2018). 


\section{La vivienda social como punto de llegada de recorridos complejos y heterogéneos}

\section{DESDE DÓNDE VIENEN: SEIS TIPOS DIFERENTES DE TRAYECTORIA RESIDENCIAL}

A partir los modos de inscripción territorial en los 20 años anteriores a la vivienda social y en sus hogares de origen hemos construido seis tipos de trayectoria residencial. Los primeros tres tipos de trayectoria tienen en común el hecho de ser los grupos que concentran mayor cantidad de población migrante y que, una vez que estos recorridos se emplazan en Buenos Aires, suelen hacerlo en entornos de hábitat informal. Además, tienden a ser destinatarios de la vivienda social en el barrio Padre Mugica (73\% de los ego que integran el tipo 1 , y el $83 \%$ del tipo 2 y 3 ).

Sin embargo, y a riesgo de trabajar con grupos numéricamente pequeños y estadísticamente no significativos, bajo el esfuerzo de comprender a modo exploratorio las dinámicas particulares que muestran las relaciones entre las tres variables analizadas, subdividimos el análisis a partir de grupos que presentan lógicas diversas. Denominamos al primer tipo de trayectoria como "migrantes recientes que acceden a las mejores posiciones urbanas ingresando a la informalidad". Son personas que en su mayoría nacieron en otros países o provincias (84\%) bajo hábitats formales y arreglos principalmente de propiedad formal, aunque también de allegamiento. Gran parte de sus vidas transcurrieron en sus países o provincias de origen y muestran procesos migratorios hacia el Área Metropolitana de Buenos Aires (AMBA), bastante recientes y próximos al momento de ingreso a la vivienda social. Al hablar de procesos migratorios resulta difícil comprender cómo estas mudanzas modifican las posiciones urbanas de los hogares, aunque es posible señalar que, en este movimiento, debieron volcarse en gran medida hacia canales informales de acceso al suelo y a la vivienda, novedosos en sus biografías. Llegados a la nueva ciudad, sus recorridos dan cuenta de grandes conquistas urbanas en la medida en que logran acceder a las zonas más valorizadas de la ciudad central y con mayores externalidades urbanas. Desde ya, es posible que los canales informales de acceso a tales posiciones devengan en obstrucciones para la apropiación de tales oportunidades urbanas.

$\mathrm{Al}$ interior de estas trayectorias se observan principalmente tres tipos de derroteros en torno al acceso a la ciudad: $27 \%$ por ciento de los casos luego de migrar se instalan directamente en las zonas de mayores externalidades, mientras que un $20 \%$ accede a las mismas luego de recorrer otras zonas menos favorables, dando cuenta de trayectorias intraurbanas ascendentes. Por último, el 27\% de estos casos, una vez que llegan al AMBA desarrollan recorridos más oscilantes que, aunque llegan a las zonas más valiosas, implican retrocesos e incluso a veces retornos a los lugares de origen por algunas etapas residenciales. 


\section{粼 revistainvi}

Figura 4.

Características de las trayectorias tipo 1, 2 y 3.
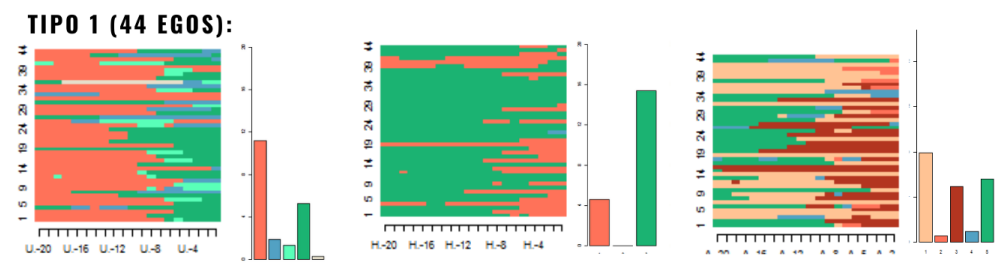

TIPO 2(36 EGOS):
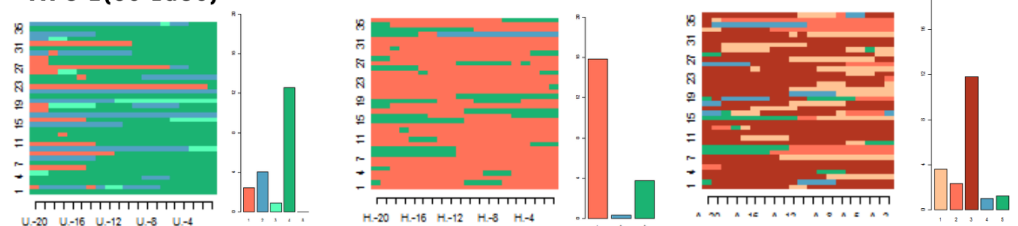

TIPO 3(18 EGOS):
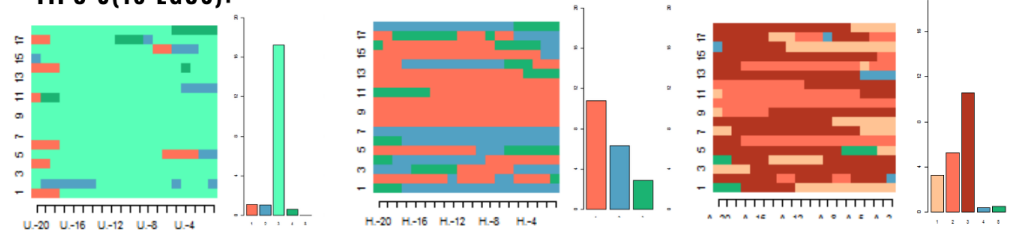

$\square$ OTRO PAÍS/PROVINCIA

$\square$ GBA

$\square$ HÁBITAT INFORMAL

$\square$ ALLEGAMIENTO

$\square$ CABA MENOS VALOR

$\square$ SOLUCIÓN ESTATAL

$\square$ ALQUILER INFORMAL

$\square$ CABA MÁS VALOR

$\square$ HÁBITAT FORMAL

$\square$ PROPIEDAD INFORMAL/OCUPANTE

$\square$ ALQUILER FORMAL

$\square$ PROPIEDAD FORMAL

INSCRIPCIÓN TERRITORIAL DE HOGARES DE ORIGEN

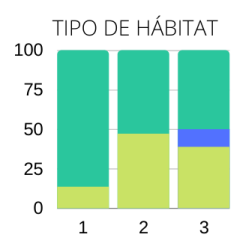

INFORMAL

SOLUCIÓN

HABITACIONAL ESTATAL FORMAL

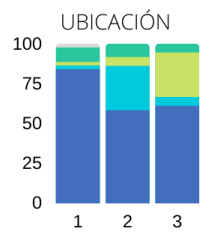

OTRO PAÍS O PROVINCIA GBA

CABA VALORIZADA

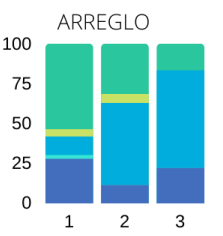

ALLEGAMIENTO, VIVIENDA COLECTIVA, ETC. ALQUILER INFORMAL

PROPIEDAD INFORMAL/OCUPACIÓN

PROPIEDAD FORMAL

Fuente: elaboración propia en base a Encuesta de Movilidad Espacial (2015-2019) 


\section{*.*vis revistainvi}

Denominamos al segundo tipo de trayectorias residenciales como "las que atravesaron mejoras tempranas de ubicación y permanecen en la informalidad". Este tipo de trayectoria se caracteriza por su inscripción en entornos de hábitat informal o bajo arreglos informales por largos periodos de tiempo, una situación que, a diferencia del tipo 1, muchos arrastran desde sus hogares de nacimiento. El 28\% de los casos nace en la Provincia de Buenos Aires y 58\% en otros países o provincias y atraviesan, al igual que el primer grupo, procesos migratorios hacia el AMBA aunque con anterioridad, principalmente a lo largo de la década del 90. Además, las migraciones ocurren más temprano en el marco de sus ciclos de vida, por lo que transitan más tiempo en el AMBA antes de acceder a la vivienda social. Al igual que las trayectorias tipo 1, estas también acceden en algún momento de sus trayectorias a las zonas de mayor externalidad de la ciudad, ya sea directamente luego de los movimientos migratorios, tras procesos de ascenso residencial en el AMBA, o como resultado de recorridos más oscilantes. Pero, pese a que estos hogares logran acceder a las zonas de mayor externalidad de la ciudad, viviendo allí por largos periodos de sus vidas -demostrando mejoras posicionales a través de sus recorridos residenciales-, reproducen los antiguos mecanismos informales de acceso al suelo y a la vivienda en estos nuevos contextos.

El tercer tipo de trayectoria reúne a quienes a lo largo de sus recorridos buscan mejoras, pero encuentran un tope en la CABA desvalorizada y en la continuidad de entornos informales. En este tipo de trayectoria al igual que en los tipos uno y dos, muchos casos migraron desde otros países o provincias (61\% de los ego). Tal como los migrantes del tipo dos, atravesaron estos movimientos a lo largo de la década del 90, situando una gran cantidad de años de vida en el AMBA. Sin embargo, a diferencia de los dos grupos previos, una vez en la Ciudad estos casos no logran acceder a las zonas de mayor externalidad urbana, sino que residen principalmente en los barrios menos valorizados, también bajo hábitats principalmente informales o modalidades de arreglos informales que fueron arrastrados desde sus hogares de origen. Junto a los migrantes, este grupo incluye a egos que nacieron y vivieron durante gran parte de su vida en los barrios desvalorizados de la CABA bajo mecanismos informales de inserción territorial. En resumen, se trata de egos que habiendo migrado temprano o siendo nativos de esta ciudad, pasan gran parte de los 20 años previos a la vivienda social en los barrios de menores externalidades, encontrando obstáculos para acceder a las zonas de mayor valor. Finalmente, sus trayectorias evidencian que a lo largo de su vida transitaron previamente por soluciones habitacionales estatales, lo cual problematiza la capacidad de estas intervenciones para dar respuestas definitivas a las problemáticas habitacionales.

En el próximo apartado nos preguntamos en qué medida la vivienda social les permitió a estos tres primeros grupos, llegados principalmente al barrio Padre Mugica, revertir las lógicas de inserción territorial informal que caracterizaron sus trayectorias (y en el primer grupo recuperar la formalidad de origen), habilitando nuevos entornos de hábitat y arreglos residenciales. Por otro lado, nos preguntamos si para el grupo 3, la vivienda social opero habilitando mejoras locacionales, es decir, el acceso a las zonas de mayor externalidad de la ciudad. Asimismo, para los dos primeros grupos, quienes ya habían conquistado estas posiciones en sus recorridos residenciales previos, nos preguntamos si la política logró garantizar y resguardar tales ubicaciones bajo canales formales. 


\section{粼 revistainvi}

Las trayectorias tipo 4 y 5 (ver Figura 5 página 17) presentan algunas características similares, como por ejemplo: tienden a ingresar a la vivienda social de Piedrabuena (78\% y 76\% de los ego respectivamente) y a desarrollar recorridos principalmente formales. Es decir que nacen en hogares que se inscriben formalmente en el hábitat y bajo arreglos residenciales formales y reproducen estas modalidades a lo largo de sus vidas tal como se puede apreciar en los recorridos de los 20 años previos a la vivienda social. Sin embargo, algunas particularidades pueden destacarse a partir de la división de estos casos en dos grupos diferentes. Las trayectorias tipo cuatro se caracterizan por una fuerte linealidad. Arrastran a lo largo de sus vidas gran parte de los elementos de sus hogares de nacimiento. Mayormente se trata de egos que nacen en el Gran Buenos Aires (64\% de los casos), y estas trayectorias se inscriben casi por completo en estas mismas posiciones urbanas, bajo mecanismos formales de acceso al suelo y la vivienda. En términos de posición urbana, sus trayectorias son principalmente lineales (64\%) y solo un 14\% logra alcanzar mejores posiciones, aunque lo hacen principalmente con recorridos oscilantes. A diferencia de los tipos de trayectorias revisados previamente, en este caso, la priorización de los mecanismos formales de acceso al hábitat parece haber trabado las posibilidades de alcanzar mejores localizaciones en la ciudad. No obstante, estos recorridos si atraviesan modificaciones en sus arreglos residenciales, principalmente en la medida que deben abandonar hogares autónomos y propietarios de origen, para al independizarse pasar a arreglos de allegamiento y de tipo de tenencia de alquiler. De cualquier modo, no se trata de cambios en los arreglos que, como en el tipo de trayectoria 1, involucra el ingreso a la informalidad urbana.

El quinto tipo de trayectoria, a diferencia de la que recién caracterizamos, reúne a egos que nacieron en los barrios menos valorizados de la CABA (45\%) y a otros que migran desde otros países o provincias temprano (32\%). Durante los 20 años anteriores a la vivienda social estos hogares residen principalmente en las zonas menos valorizadas de la CABA en inscripciones formales. Al igual que las anteriores, residen principalmente (54\% de los casos) en estas zonas como resultado de trayectorias lineales, ya sea porque viven allí desde su nacimiento o bien porque, luego de migrar desde sus países o provincias de origen; llegan a estas zonas y permanecen. En segundo lugar, el $41 \%$ de los casos residen en estas zonas menos valorizadas como resultado de movimientos ascendentes y oscilantes. Esto último da cuenta de que el acceso a las zonas aún menos valorizadas de la ciudad central, son resultado de luchas posicionales por el acceso a las externalidades urbanas con alcances limitados e inestables. Al igual que el grupo anterior, las estrategias enteramente formales de acceso al suelo y a la vivienda podrían haber limitado las posibilidades de estos hogares de acceder a mejores ubicaciones y bajo modalidades de tenencia que habiliten mayor estabilidad. También se registra que en la mayoría de los movimientos residenciales los hogares recurren al allegamiento (principalmente para salir de sus hogares de origen) y también al alquiler formal como canal de autonomía del hogar de origen o para obtener situaciones de independencia del allegamiento.

Respecto a estos dos grupos de trayectorias que acceden principalmente al barrio Piedrabuena, nos preguntaremos en el próximo apartado si el ingreso a la vivienda social logró motorizar mejoras en sus posiciones urbanas, y si brindó oportunidades de autonomía (mediante canales formales) para los hogares allegados. 


\section{粼 revistainvi}

Figura 5.

Características de las trayectorias tipo 3 y 4.

IIPO 4 (28 EGOS):
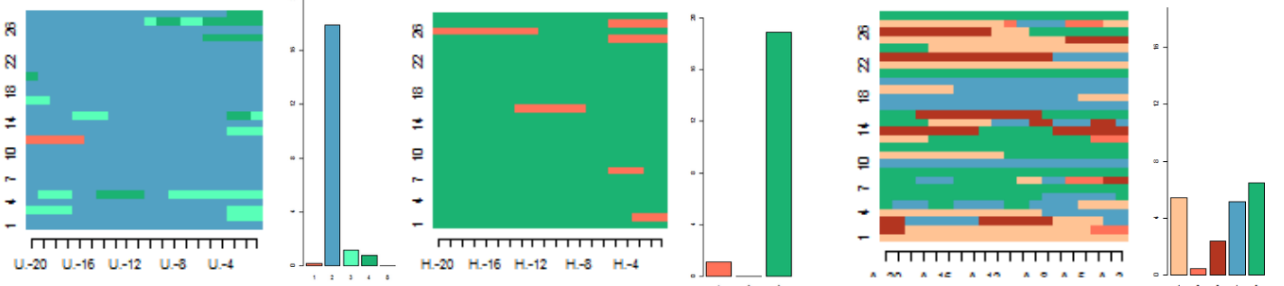

TIPO 5(44EGOS):
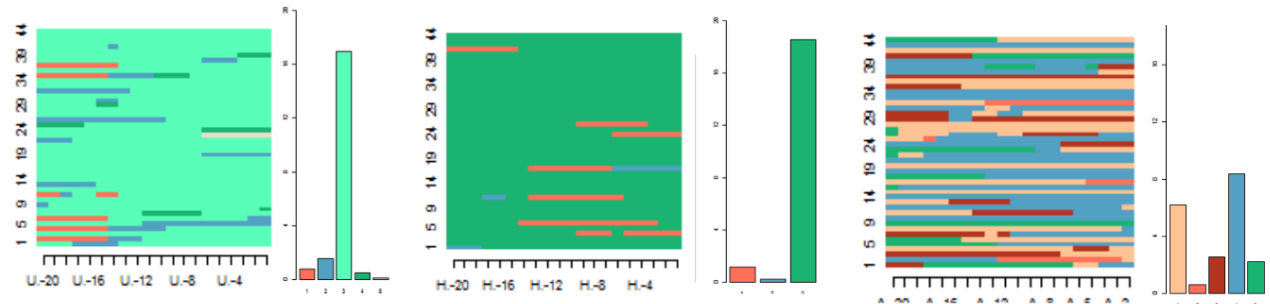

$\square$ OTRO PAÍS/PROVINCIA

$\square$ GBA

$\square$ HÁBITAT INFORMAL

$\square$ ALLEGAMIENTO

$\square$ CABA MENOS VALOR

$\square$ SOLUCIÓN ESTATAL

$\square$ ALQUILER INFORMAL

$\square$ CABA MÁS VALOR

$\square$ HÁBITAT FORMAL

$\square$ PROPIEDAD INFORMAL/OCUPANTE

$\square$ ALQUILER FORMAL

$\square$ PROPIEDAD FORMAL

\section{INSCRIPCIÓN TERRITORIAL DE HOGARES DE ORIGEN}

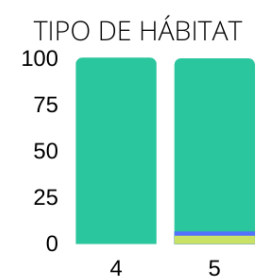

INFORMAL

HABITACIONAL ESTATAL FORMAL

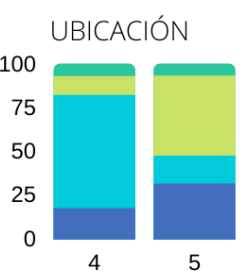

OTRO PAÍS O PROVINCIA GBA

CABA DESVALORIZADA

CABA VALORIZADA

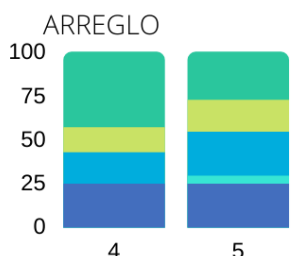

ALLEGAMIENTO, VIVIENDA COLECTIVA, ETC. ALQUILER INFORMAL

PROPIEDAD INFORMAL/OCUPACIÓN

ALQUILER FORMAL

PROPIEDAD FORMAL

Fuente: elaboración propia en base a Encuesta de Movilidad Espacial (2015-2019). 


\section{*.*vis revistainvi}

Por último, el sexto tipo de trayectoria residencial (ver Figura 6 página 19) reúne a "quienes nacen o llegan a las zonas más deseadas de la ciudad bajo modalidades invisibles de informalidad" y representa principalmente a los hogares que fueron destinatarios de la vivienda social en la traza de la Ex AU3 (77\%). A diferencia de los otros tipos, nacieron principalmente en los barrios más valorizados de la CABA bajo hábitats formales y han vivido durante gran parte de su vida en estas localizaciones, habilitando un acceso prolongado a las externalidades positivas que brinda la ciudad. Si bien también reúne a egos que nacieron en otros países o provincias (30\%) y migraron a Buenos Aires durante la década del 90 e incluso en periodos anteriores, estos se instalaron en las zonas más valorizadas al llegar a la ciudad y lo hicieron, a diferencia de las trayectorias del tipo 1 y 2 , en entornos de hábitats predominantemente formales. Sin embargo, su inscripción territorial fue informal, ya que aunque en tipos de hábitat formales desplegaron estrategias de propiedad informal o la ocupación de hecho. Esta modalidad de informalidad "puertas adentro", aparece en varios casos presente desde los hogares de origen, reproduciéndose a lo largo de las trayectorias. Cabe destacar que, aunque estas trayectorias se inscriben principalmente en zonas de mayores externalidades urbanas, dan cuenta de recorridos oscilantes en torno a las mismas. Podemos leer estas idas y vueltas como procesos de resistencia ante desplazamientos de una zona valiosa (y como ya mencionamos, disputada) de la ciudad, como lo son los barrios que integran la traza de la EX AU3.

Por último, y al igual que las trayectorias tipo 3, estas muestran la presencia de soluciones habitacionales brindadas por el Estado en etapas previas de sus vidas. En torno a los efectos particulares que podríamos esperar de la vivienda social sobre este grupo, en el próximo apartado nos preguntamos si las viviendas construidas para la traza de la Ex AU3 resguardaron las ubicaciones privilegiadas que estos hogares habían conquistado previamente en la ciudad y, si lo hicieron, fue garantizando modalidades de acceso al suelo y la vivienda formales que permitan hacer duraderas tales posiciones urbanas.

Como hemos visto hasta aquí, los seis tipos de trayectoria residencial muestran que los recorridos previos a la vivienda social son heterogéneos. Reflejan desigualdades iniciales y otras que se forjaron a lo largo de las trayectorias mediante estrategias residenciales muy diversas para satisfacer sus necesidades y expectativas habitacionales en el marco escenarios particulares. Este abanico de estrategias da cuenta de la acumulación y disposición de distintos capitales del curso de vida con los que los hogares hicieron frente a distintos riesgos (O'Rand, 1996, 2001). El análisis de las trayectorias residenciales y la tipología resultante da cuenta de que estos hogares llegan a la vivienda social con diferentes grados de vulnerabilidad producto de procesos biográficos (Saraví, 2007), que favorecieron a la producción de diversas estrategias residenciales (Di Virgilio, 2008) y dieron como resultado diferentes derroteros en sus luchas por la apropiación del espacio urbano (Bourdieu, 1999). A continuación, nos preguntamos en qué medida estas distintas trayectorias inciden en los efectos diferenciales que produce la vivienda social sobre estos hogares. 


\section{粼 revistainvi}

\section{Figura 6.}

Características de las trayectorias tipo 6.

\section{IIPO 6 (70 EGOS):}
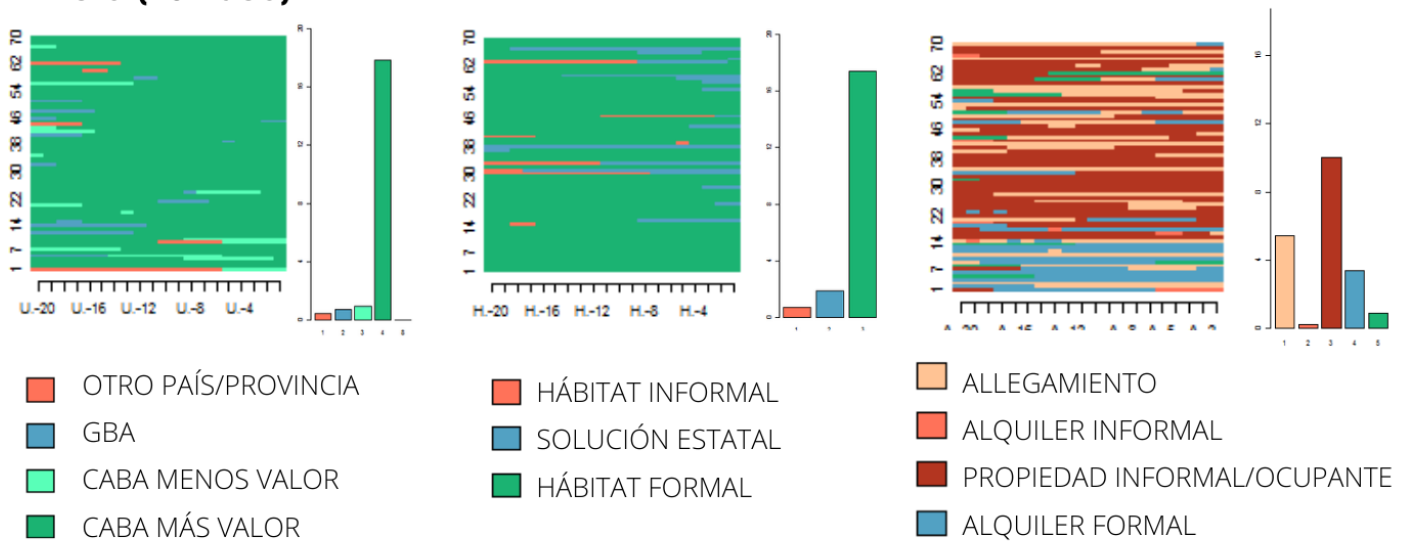

$\square$ ALLEGAMIENTO

$\square$ ALQUILER INFORMAL

$\square$ PROPIEDAD INFORMAL/OCUPANTE

$\square$ ALQUILER FORMAL

$\square$ PROPIEDAD FORMAL

\section{INSCRIPCIÓN TERRITORIAL DE HOGARES DE ORIGEN}

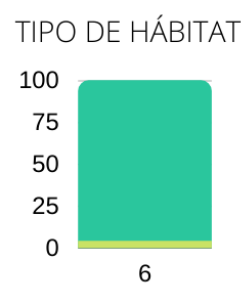

NFORMAL

SOLUCIÓN

HABITACIONAL ESTATAL FORMAL

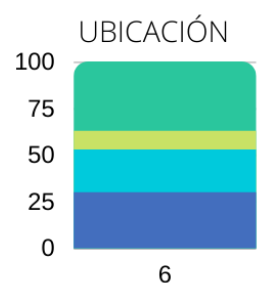

OTRO PAÍS O PROVINCIA GBA

CABA DESVALORIZADA CABA VALORIZADA

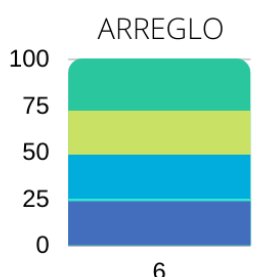

ALLEGAMIENTO, VIVIENDA COLECTIVA, ETC. ALQUILER INFORMAL PROPIEDAD INFORMAL/OCUPACIÓN ALQUILER FORMAL PROPIEDAD FORMAL

Fuente: elaboración propia en base a Encuesta de Movilidad Espacial (2015-2019). 


\section{*.*vis revistainvi}

\section{HACIA dónde VAN: EL EFECTO de LLEGAR a LA VIVIENDA SOCIAL PARA LOS DISTINTOS TIPOS DE TRAYECTORIA RESIDENCIAL}

Aquí reflexionaremos acerca de la capacidad desigual de la vivienda social para transformar positivamente a las distintas trayectorias residenciales, indagando los impactos del ingreso a estas viviendas sobre sus localizaciones y arreglos residenciales. Asimismo, tendremos en cuenta las "conquistas" en torno al acceso a la ciudad que los seis tipos de trayectoria residencial visibilizaron en sus recorridos previos, así como las trabas u obstáculos a los que se enfrentaron para identificar en qué medida la política de vivienda social consideró y buscó resguardar tales "conquistas" y resolver aquellos obstáculos en pos de mejorar las inscripciones territoriales de sus destinatarios.

En primer lugar, observamos que las probabilidades de mejorar las oportunidades urbanas asociadas a las posiciones en la ciudad fueron distintas para los seis tipos de trayectoria. Esto se vincula, por un lado, a las posiciones desiguales que los tres casos de vivienda social tienen en el territorio, así como a las posiciones territoriales que caracterizaron a los hogares que integran los diferentes tipos de trayectoria. Sobre este punto debemos recordar que aunque los tres barrios de vivienda social se ubican en la ciudad central, lo hacen en zonas desiguales: el barrio Piedrabuena y Padre Mugica se ubican en la zona menos favorecida de la ciudad y las viviendas de AU3 a lo largo de una traza que atraviesa barrios con mayor acceso a externalidades urbanas favorables.

Tal como vemos en la Tabla 2, quienes protagonizaron las trayectorias residenciales tipo 4 tuvieron mayores probabilidades de mejorar su posición urbana. Se trata de aquellos que, como habíamos mencionado, tienden a llegar al barrio Piedrabuena, ubicado en la ciudad central en una de las zonas con menor acceso a externalidades de la misma. Sin embargo, como sus trayectorias se habían emplazado principalmente (y linealmente) en el Gran Buenos Aires, la vivienda social opera sobre las mismas como puerta de acceso a la ciudad central, aunque se trate de su área más deficitaria.

En cambio, para el resto de los tipos de trayectoria que mostraban una presencia previa en la CABA, la vivienda social no habilitó mejoras ni acceso a mejores posiciones. No obstante, el primer tipo de trayectoria, caracterizada por reunir a migrantes más recientes y por desembocar principalmente en barrio Padre Mugica, muestra una probabilidad levemente superior a mejorar las localizaciones tras la vivienda social. Se trata de aquellos hogares que como mencionamos en el apartado anterior, a pesar de que lograron residir en las zonas más valorizadas, lo hicieron en el marco de recorridos inestables y fluctuantes y para quienes, la etapa residencial previa a la vivienda social se emplazó a mayor distancia de estas zonas que supieron conquistar. Entonces, aun para estos hogares que mejoran sus posiciones urbanas con la vivienda social, debido a que esta se ubica en las áreas de menor valor de la ciudad central, no logran recuperar aquellas posiciones más valiosas previamente alcanzadas. 
Tabla 2 .

Efecto de ingreso a la vivienda social sobre localización, según tipo de trayectoria residencial.

\begin{tabular}{llll} 
Tipo de trayectoria & Efecto negativo & Efecto reproductor & Efecto positivo \\
\hline tipo 1 & $48 \%$ & $18 \%$ & $34 \%$ \\
\hline tipo 2 & $72 \%$ & $19 \%$ & $8 \%$ \\
\hline tipo 3 & $0 \%$ & $83 \%$ & $17 \%$ \\
\hline tipo 4 & $7 \%$ & $21 \%$ & $71 \%$ \\
\hline tipo 5 & $7 \%$ & $86 \%$ & $7 \%$ \\
\hline tipo 6 & $16 \%$ & $83 \%$ & $1 \%$ \\
\hline
\end{tabular}

Fuente: elaboración propia en base a Encuesta de Movilidad Espacial (2015-2019).

Cabe destacar que para la mayoría de las trayectorias que integran el tipo 1, así como el tipo 2 (las cuales tendieron a alcanzar mejores posiciones urbanas y acceden a la vivienda social en el barrio Padre Mugica), el efecto es principalmente negativo, involucrando pérdidas en sus ganancias locacionales de acceso a externalidades urbanas. Por el contrario, quienes habitaban las zonas de mayores externalidades en las trayectorias tipo 6 (quienes ingresan principalmente a las viviendas de AU3 ubicadas en estas mismas zonas), reproducen sus localizaciones. Para estos casos, el efecto reproductor habilita el resguardo de conquistas urbanas alcanzadas en sus trayectorias. Sin embargo, el efecto reproductor sobre la localización residencial que se observa predominantemente en las trayectorias tipo 5 y tipo 3, muestra que quienes en sus luchas por el acceso a la ciudad alcanzaron las zonas más deficitarias de la ciudad central, la vivienda social (ubicada en estas mismas áreas), no destraba los obstáculos a los que estos hogares se encontraron previamente en sus recorridos hacia mejores posiciones.

En segundo lugar, identificamos efectos diferenciales del acceso a la vivienda social sobre los arreglos residenciales para los diferentes tipos de trayectorias. 


\section{*.*vis revistainvi}

Tabla 3.

Efectos de la vivienda social sobre los arreglos residenciales, según tipo de trayectoria residencial.

\begin{tabular}{lllll} 
Tipo de trayectoria & Acceso a autonomía & Efecto negativo & Efecto reproductor & $\begin{array}{l}\text { Efecto positivo en } \\
\text { tenencia }\end{array}$ \\
\hline tipo 1 & $23 \%$ & $2 \%$ & $52 \%$ & $23 \%$ \\
\hline tipo 2 & $25 \%$ & $6 \%$ & $55 \%$ & $14 \%$ \\
\hline tipo 3 & $22 \%$ & $11 \%$ & $39 \%$ & $28 \%$ \\
\hline tipo 4 & $21 \%$ & $22 \%$ & $18 \%$ & $39 \%$ \\
\hline tipo 5 & $25 \%$ & $18 \%$ & $25 \%$ & $32 \%$ \\
\hline tipo 6 & $24 \%$ & $9 \%$ & $43 \%$ & $24 \%$ \\
\hline
\end{tabular}

Fuente: elaboración propia en base a Encuesta de Movilidad Espacial (2015-2019).

En general, para el total de los encuestados que habitan la vivienda social llama la atención el gran porcentaje de efecto reproductor sobre sus arreglos residenciales, principalmente para aquellos que desarrollaban previamente modalidades de acceso al suelo y a la vivienda informales (trayectoria tipo 1, tipo 2, tipo 3 y tipo 6). Este aspecto se vincula con la llamativa pero reconocida característica precaria de la tenencia de la vivienda social, tributaria de los demorados procesos de escrituración de las unidades (Defensoría del Pueblo de la Ciudad Autónoma de Buenos Aires, 2015; Najman, 2020). Como consecuencia, si la mayoría de estas trayectorias se habían encontrado previamente obstáculos para acceder a las modalidades de inscripción territorial formal, la vivienda social no parece generar (al menos en el corto plazo) soluciones a dicha problemática. De hecho, el barrio Piedrabuena que como mencionamos al inicio se trata del caso de vivienda social histórico, al haber avanzado (aunque no completamente) en su proceso de escrituración habilita en cierta medida una mejora en los arreglos de las trayectorias tipo 4 y 5 que llegan allí. Mientras que quienes llegaron a ese barrio y aún esperan la escrituración de sus viviendas, perciben una desmejora de sus arreglos, los cuales en sus trayectorias previas se caracterizaban por modalidades estrictamente regulares.

A pesar de lo anterior, la vivienda social en los tres casos de estudio, y para todos los tipos de trayectorias, habilita una mejora sobre los arreglos residenciales previos a través del acceso a la autonomía e independencia de los hogares nucleares. La vivienda social se presenta entonces como un canal para resolver una problemática similar que enfrentaban hogares con trayectorias y estrategias residenciales muy diversas como consecuencia de los mecanismos expulsivos y restrictivos del mercado de tierra y vivienda local. 


\section{*.*vis revistainvi}

\section{Reflexiones finales}

Como mencionábamos en la introducción de este trabajo, la política de vivienda social local ha sostenido a lo largo del tiempo un abordaje homogeneizante de sus destinatarios, tendiendo a igualar unas problemáticas diversas ante la oferta de una solución uniforme y muchas veces insuficiente. Frente a este supuesto vigente y sostenido en la intervención pública, el análisis de las trayectorias residenciales desarrollado en este artículo visibilizó que aquellos quienes llegaron a la vivienda social lo hicieron mediante historias particulares que señalan una profunda heterogeneidad entre los destinatarios. Asimismo, hemos advertido que los efectos asociados al ingreso a la vivienda social fueron distintos para quienes habían protagonizado trayectorias diferentes y que por lo tanto llegaban a la vivienda social con necesidades diversas. Estos dos elementos sugieren la potencialidad de pensar a las trayectorias residenciales como un factor de diferenciación sobre eventos relevantes, como es el ingreso a la vivienda social.

Los recorridos previos de estos habitantes visibilizaron derroteros muy diversos en relación a sus situaciones de origen, a los recursos con los que contaron para desplegar distintas estrategias habitacionales y a los modos en que resolvieron situaciones de riesgo del curso de vida. Sus trayectorias dieron cuenta de diversas conquistas y obstáculos en sus luchas por el acceso a la ciudad, demostrando que los habitantes de la vivienda social llegan a la misma expresando situaciones heterogéneas de exclusión socio-territorial.

Por otro lado, la reconstrucción de las trayectorias residenciales a partir de un análisis cuantitativo y multinivel iluminó un campo metodológico interesante y apropiado para la exploración de fenómenos urbanos bajos un enfoque biográfico y multidimensional. Futuros trabajos podrían explorar, bajo esta perspectiva, las relaciones entre las trayectorias residenciales y socio-ocupacionales o podrían nutrir las tradicionales investigaciones vinculadas a la movilidad espacial desde una mirada demográfica centrada en el ciclo de vida de las familias.

Finalmente, el análisis de las trayectorias residenciales de los habitantes de la vivienda social nos permitió problematizar los efectos de estas soluciones habitacionales sobre las condiciones de vida, y principalmente residenciales, de sus destinatarios. Advertimos que, a pesar de que el alcance transformador en términos positivos de estas intervenciones estatales es muy limitado para el total de los encuestados, existen diferencias sustanciales a partir de las trayectorias previas que estos hogares habían protagonizado. Las viviendas sociales ubicadas en las zonas menos ventajosas de la ciudad no lograron resguardar las conquistas urbanas que gran parte de sus destinatarios habían alcanzado en sus trayectorias previas, mientras que sí significaron mejoras posicionales para quienes en sus trayectorias anteriores no habían logrado acceder a estas zonas de la ciudad. Las viviendas ubicadas en los barrios de mayores externalidades urbanas sí lograron resguardar las posiciones urbanas que sus destinatarios habían alcanzado previamente. Por otro lado, en relación a los arreglos residenciales de los hogares y la característica formal o informal urbana de los mismos, la vivienda social no parece haber logrado mejoras sustanciales sobre este punto en las trayectorias que habían presentado 


\section{粼 revistainvi}

serios obstáculos para acceder al suelo y a la vivienda mediante mecanismos formales. No obstante, la vivienda social en todos los casos y para todas las trayectorias significó la posibilidad de muchos destinatarios de acceder a la independencia y autonomía de sus hogares, dando cuenta de un aspecto positivo común sobre todos los casos.

Si a lo largo del análisis de las trayectorias previas a la vivienda social pudimos advertir que en sus luchas por el acceso a la ciudad, estos hogares habían enfrentado distintos tipos de obstáculos y alcanzado situaciones de conquista desiguales, las soluciones habitacionales no parecen haber incorporado estas necesidades y particularidades en sus diseños. La falsa igualación de los destinatarios de la vivienda social ha operado como soporte para impedir que estas políticas logren sostener los "éxitos" y resolver los "obstáculos" que los hogares protagonizaron previamente en sus trayectorias residenciales. 


\section{Referencias bibliográficas}

Bartolomé, L. (2008). GPDs y desplazamientos poblacionales: algunas claves para su comprensión como procesos sociales complejos. Itha Revista de Antropologia, 10(1), 8-25. https://doi.org/10.5007/2175-8034 2008v10n1p8

Bourdieu, P. (1999). Efectos de lugar. En P. Bourdieu (Dir.), La miseria del mundo. Fondo de Cultura Económica.

Clark, W. (2013). Life course events and residential change: unpacking age effects on the probability of moving. Journal of Population Research, 30(4), 319-334. https:// doi.org/10.1007/s12546-013-9116-y

Colombi, D. y Paye, S. (2014). Synchronising sequences. An analytic approach to explore relationships between events and temporal patterns. En P. Blanchard, F. Bühlmann, y J.-A. Gauthier (Eds.), Advances in sequence analysis: Theory, method, applications (pp. 249264). Springer.

Cosacov, N. (2014). Habitar la centralidad. Trayectorias residenciales y usos cotidianos del espacio urbano de residentes en Caballito, Buenos Aires. (Tesis de doctorado, sin publicar). Facultad de Ciencias Sociales, Universidad de Buenos Aires, Buenos Aires.

Defensoría del Pueblo de la Ciudad Autónoma de Buenos Aires. (2015). Informe programa de rehabilitación y puesta en valor de conjuntos urbanos.

Dewilde, C. (2003). A life-course perspective on social exclusion and poverty. The British Journal of Sociology, 54(1), 109-128. https://doi.org/10.1080/0007131032 $\underline{000045923}$

Di Virgilio, M. M. (2008). Trayectorias residenciales y estrategias habitacionales de familias de sectores populares y medios en Buenos Aires. (Tesis de doctorado, sin publicar). Universidad de Buenos Aires, Buenos Aires, Argentina.).
Dieleman, F. M. (2001). Modelling residential mobility; a review of recent trends in research. Journal of Housing and the Built Environment, 16(3-4), 249-265. https://doi.org/10.1023/A:1012515709292

Dureau, F. (2004). Sistemas residenciales. Conceptos y aplicaciones. Territorios, (10-11), 41-70.

Dureau, F., Córdoba, H., Flórez, C. E., Le Roux, G., Lulle, T., y Miret, N. (2011). Encuestas movilidad espacial Bogotá METAL 2009. Metodología de las encuestas. Serie Documentos CEDE, (23).

Elder, G. (1991). Lives and social change. En W. Heinz (Ed.), Theoretical advances in life course research. status passages and the life course. Deutscher Studien Verlag

Gabadinho, A., Ritschard, G., Müller, N. S., y Studer, M. (2011). Analyzing and visualizing state sequences in $\mathrm{R}$ with TraMineR. Journal of Statistical Software, 40(4), 1-37. https://doi.org/10.18637/jss.v040.i04

Gauthier, J. A., Widmer, E. D., Bucher, P., y Notredame, C. (2010). Multichannel sequence analysis applied to social science data. Sociological methodology, 40(1), 1-38. https://doi.org/10.1111/j.1467-9531.2010.01227.x

Giglia, A. (1996). La democracia en la vida cotidiana. Dos casos de gestión de condominios en la Ciudad de México. Alteridades, 6(11).

Girola, M. F. y Thomasz, A. G. (2014). Del "derecho a la vivienda" al "derecho a la cultura": reflexiones sobre la constitución del "derecho a la ciudad" en Buenos Aires desde una perspectiva etnográfica. Anuário Antropológico, 38(2), 131-163. https://doi.org/10.4000/aa.593

Harvey, D. (1977). Urbanismo y desigualdad social. Siglo XXI.

Helske, S., Helske, J., y Eerola, M. (2018). Combining sequence analysis and hidden Markov models in the analysis of complex life sequence data. En 
Sequence Analysis and Related Approaches (pp. 185200). Springer.

Howley, P. (2009). Attitudes towards compact city living: Towards a greater understanding of residential behavior. Land Use Policy, 26(3), 792-798. https://doi. org/10.1016/j.landusepol.2008.10.004

Lefebvre, H. (1968). El derecho a la ciudad. Ediciones Península.

Lévy, J. P. (1998). Habitat et habitants: position et mobilité dans l'espace résidentiel. En Y. Grafmeyer, y F. Dansereau (Eds.), Trajectoires familiales et espaces de vie en milieu urbain. Presses Universitaires de Lyon.

Martínez Salgado, M., y Ferraris, S. (2021). Género y trabajo. El sostenimiento económico de los hogares en México. Revista Latinoamericana de Población, 15(28), 179-204.

https://doi.org/10.31406/relap2021.v15.i1.n28.7

Mera, G. S., Di Virgilio, M. M. y Marcos, M. (2015). Las ciudades dentro de la ciudad: características sociodemográficas y habitacionales de la Ciudad de Buenos Aires según sus tipos de hábitat. Población de Buenos Aires, 12(22), 33-57.

Najman, M. (2020). ¿Vivir mejor? Análisis de las trayectorias hacia la vivienda social y las transformaciones sobre las situaciones de exclusión de sus habitantes. (Tesis de doctorado en Ciencias Sociales) Universidad de Buenos Aires, Argentina.

O'Rand, A. M. (1996). The cumulative stratification of the life course. En R. H. Binstock y L.K. George (Eds.), Handbook of aging and the social sciences, (pp. 188207). Academic Press.

O'Rand, A. M. (2001). Stratification and the life course: The forms of life-course capital and their interrelationships. En R. H. Binstock y L. K. George (Eds.), Handbook of aging and the social sciences (pp. 197-213). Academic Press.
Oszlak, 0. (1991). Merecer la ciudad: los pobres y el derecho al espacio urbano. Cedes.

Palomares-Linares, I., Feria, J. M. y Susino, J. (2017). Medida y evolución de la movilidad residencial en las áreas metropolitanas españolas. Papers. Revista de Sociología, 102(4), 545-574. https://doi.org/10.5565/ rev/papers. 2412

Pinto da Cunha, J. M. (2012). Apresentação - Mobilidade espacial da população: desafios teóricos e metoᄀdológicos para o seu estudo. En J. M. Pinto da Cunha (Ed.), Mobilidade espacial da população: desafios teóricos e metodológicos para o seu estudo (pp. 7-15). Núcleo de Estudos de População-Nepo/Unicamp.

Pooley, C. G. (1997). Introduction to housing strategies in Europe. En C. G. Pooley (Ed.), Housing strategies in Europe 1880 -1930. Leicester University Press.

Ritschard, G. y Studer, M. (Eds.). (2018). Sequence analysis and related approaches: Innovative methods and applications. Springer.

Ryan, C. y Whelan, S. (2010). Locational disadvantage, socio-economic status and mobility behaviour evidence from Australia. Research School of Economics, Australian National University .

Saraví, G. (2007). Nuevas realidades y nuevos enfoques: exclusión social en América Latina. En G. Saraví (Ed.), De la pobreza a la exclusión. Continuidades y rupturas de la cuestión social en América Latina (pp. 19-52). CIESAS, Prometeo Libros.

Zapata, M. C. (2013). El programa de autogestión de la vivienda: ¿una política habitacional habilitante del derecho a la ciudad? (Tesis de maestría) Universidad de Buenos Aires. 


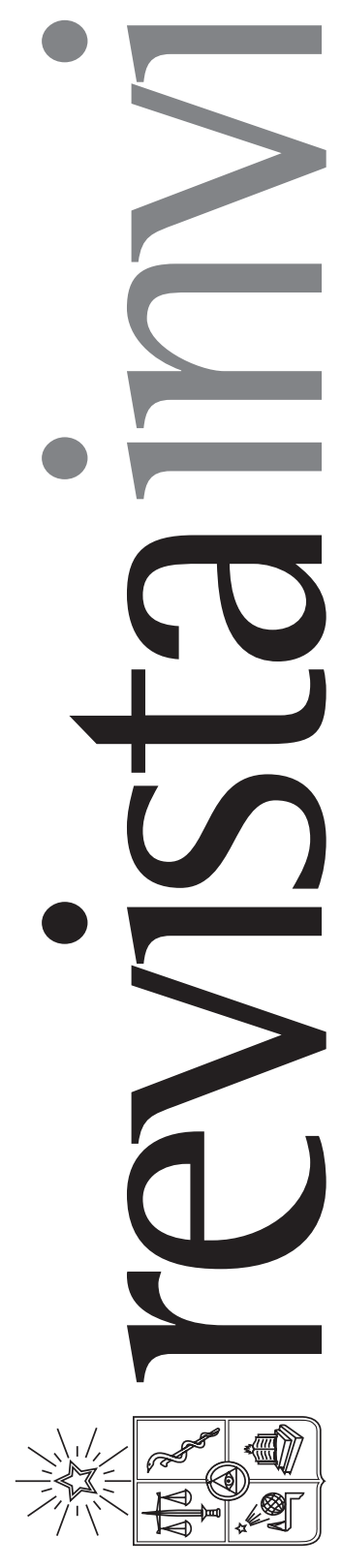

Revista INVI es una publicación periódica, editada por el Instituto de la Vivienda de la Facultad de Arquitectura y Urbanismo de la Universidad de Chile, creada en 1986 con el nombre de Boletín INVI. Es una revista académica con cobertura internacional que difunde los avances en el conocimiento sobre la vivienda, el hábitat residencial, los modos de vida y los estudios territoriales. Revista INVI publica contribuciones originales en español, inglés y portugués, privilegiando aquellas que proponen enfoques inter y multidisciplinares y que son resultado de investigaciones con financiamiento y patrocinio institucional. Se busca, con ello, contribuir al desarrollo del conocimiento científico sobre la vivienda, el hábitat y el territorio y aportar al debate público con publicaciones del más alto nivel académico.

Directora: Dra. Mariela Gaete Reyes, Universidad de Chile, Chile Editor: Dr. Luis Campos Medina, Universidad de Chile, Chile

Editores asociados: Dr. Gabriel Felmer, Universidad de Chile, Chile.

\section{Dr. Pablo Navarrete, Universidad de Chile, Chile.}

Dr. Juan Pablo Urrutia, Universidad de Chile, Chile

Coordinadora editorial: Sandra Rivera, Universidad de Chile, Chile.

Asistente editorial: Katia Venegas, Universidad de Chile, Chile.

\section{COMITÉ EDITORIAL:}

Dr. Victor Delgadillo, Universidad Autónoma de la Ciudad de México, México.

Dra. María Mercedes Di Virgilio, CONICET/ IIGG, Universidad de Buenos Aires, Argentina. Dra. Irene Molina, Uppsala Universitet, Suecia.

Dr. Gonzalo Lautaro Ojeda Ledesma, Universidad de Valparaíso, Chile.

Dra. Suzana Pasternak, Universidade de São Paulo, Brasil.

Dr. Javier Ruiz Sánchez, Universidad Politécnica de Madrid, España.

Dra. Elke Schlack Fuhrmann, Pontificia Universidad Católica de Chile, Chile.

Dr. Carlos Alberto Torres Tovar, Universidad Nacional de Colombia, Colombia.

Sitio web: http://www.revistainvi.uchile.cl/

Correo electrónico: revistainvi@uchilefau.cl

Licencia de este artículo: Creative Commons Atribución-Compartirlgual 4.0

Internacional (CC BY-SA 4.0) 